\title{
RELATED TO SERVICES THAT THE EXECUTIVES RECEIVED FROM ACCOUNTING PROFESSIONAL MEMBERS SATISFACTION OF SATISFACTION: A STUDY FOR QUALITY AND EXPECTATIONS
}

DOI: 10.17261/Pressacademia.2019.1088

PAP-V.9-2019(35)-p.175-179

Gokhan Ozer ${ }^{1}$, Abdullah Kursat Merter ${ }^{2}$, Mehmet Fetih Cati ${ }^{3}$

${ }^{1}$ Gebze Technical University, Faculty of Business Administration, Istanbul, Turkey gokozerhan@gmail.com, ORCID: 0000-0002-3255-998X

${ }^{2}$ Gebze Technical University, Faculty of Business Administration, Istanbul, Turkey, akmerter@gtu.edu.tr, ORCID: 0000-0001-6874-1890

${ }^{3}$ Gebze Technical University, Graduate School of Social Sciences, Istanbul, Turkey, fetihcati@hotmail.com, ORCID: 0000-0001-8526-6104

To cite this document

Ozer, G., Merter A.K., Cati, M.F., (2019). Related to services that the executives received from accounting professional members satisfaction of satisfaction: a study for quality and expectations. PressAcademia Procedia (PAP), V.9, p.175-179

Permemant link to this document: http://doi.org/10.17261/Pressacademia.2019.1088

Copyright: Published by PressAcademia and limited licenced re-use rights only.

\section{ABSTRACT}

Purpose- In this study, it is aimed to determine the expectations of the people benefiting from the financial consultancy service by determining the expectations of the service and determining whether the service errors made while providing the financial consultancy service are effective on the perceived service quality.

Methodology- The model, which was created within the scope of the application, was obtained by the data survey method to be used in the testing phase. The questionnaire was applied to 197 financial advisors. The collected data were analyzed by statistical package programs and structural equation model was used within the scope of the hypothesis testing.

Findings- According to the results of the analysis; It has been determined that service errors affect negatively the perceptions of service quality of taxpayers.

Conclusion- It has been concluded that service errors during the financial consultancy service reduce the satisfaction level of the taxpayer

Keywords: Service failure, financial consultancy, perceived service quality, smart pls, structural equation model

JEL Codes : M49

\section{MÜKELLEFLERIN, MUHASEBE MESLEK MENSUPLARINDAN ALDIKLARI HIZMETLERE iLIŞKIN MEMNUNIYET ÖLÇÜMLEMESI; KALITE VE BEKLENTILERINE YÖNELIK BIR ÇALIŞMA}

\section{ÖZET}

Amaç- Çalışmada, mali müşavirlik hizmetinden yararlanan kişilerin, aldıkları hizmete ilişkin tespitlerde bulunularak, bu hizmetten beklentilerinin ne olduğu ortaya koyulmaya çalışılarak, mali müşavirlik hizmeti sunulurken yapılan hizmet hatalarının algılanan hizmet kalitesine etkili olup olmadığının belirlemesi amaçlanmıştır.

Metodoloji- Uygulama kapsamında oluşturulan model, test aşamasında kullanılacak veri anket yöntemiyle elde edilmiştir. Yapılan anket ülke genelinde 197 adet mali müşavirlik hizmeti alan kişiye uygulanmıştır. Toplanan veriler istatistik paket programları vasıtasıyla analiz edilmiş olup hipotezlerin testi kapsamında yapısal eşitlik modeli kullanılmıştır.

Bulgular- Elde edilen analiz sonuçlarına göre; hizmet hatalarının mükelleflerin hizmet kalitesi algılarını negatif yönde etkilediği tespit edilmiştir.

Sonuç- Mali müşavirlik hizmeti esnasında yapılan hizmet hatalarının mükellefin memnuniyet seviyesini düşürdüğü sonucuna ulaşılmıştır.

Anahtar Kelimeler: Hizmet hatası, mali müşavirlik, algılanan hizmet kalitesi, smart pls, yapısal eşitlik modeli JEL Kodları: M49 


\section{GíRiş}

Ülkemizde faaliyette olan işletmelerin neredeyse tamamı, muhasebe meslek mensuplarının yetkileri çerçevesinde hizmet talep etmektedir. Bundan dolayı firmalara düzenli ve tam zamanlı veri aktarması umulan mali müşavirlerin sunmuş oldukları hizmetin kalite seviyesinin ve mükellef memnuniyetinin ölçülmesi oldukça ehemmiyet arz etmektedir (Banar ve Ekergil, 2010:40). Hizmet sektörünün içerisinde yer alan Mali müşavirlik hizmeti sunulurken, hizmetin özelliği gereği işin merkezinde yine insan faktörü yer almaktadır. Bu kapsamda mali müşavirler her ne kadar hatasız ve başarılı hizmet sunmayı amaç edinse de hataların yaşanması olasılık dahilindedir. Bu sebeple hizmet hatası olasılığını minimuma indirgemek, hizmet kalitesini artırılabilir.

Çalışmada, anketi mükelleflere uygulayarak hizmeti alanlar açısından kalitenin ölçülmesi amaçlanmaktadır. Araştırmada 2 sorunun cevabına ulaşılmaya çalışımıştır:

1. Mali müşavirlik hizmeti sunulurken yapılacak hizmet hataları mükellefler nezdinde algılanan hizmet kalitesini düşürür mü?

2. Çalışmada majör ve minör olarak ayrılan hizmet hatalarının, mükellefin algıladığı hizmet boyutlarından hangisini daha fazla etkilemektedir? Ayrıca bu sorudan yola çıkarak özel olarak cevabı aranan soru ise aşağıdaki gibidir:

Mali müşavirlerin hizmeti sunarken yaptıkları, çalışmada majör ve minör olarak ayrılan hizmet hatalarının, mükellefin algıladığı hizmet boyutlarından (Somut Özellikler, Güvenilirlik, Heveslilik, Güven, Empati) hangisini veya hangilerini negatif yönde etkiler?

Bu sorular kavramsal modelin incelenmesinde kılavuzluk etmesi amacıyla kullanılmıştır. Kavramsal modelde Mali müşavirlerin, hizmeti sunarken ortaya çıkabilecek hatalarının, mükellefin memnuniyetini etkileyeceğini, bu kavramlar arasında ilişki olduğu öne sürülmektedir. Araştırmanın hipotezleri de bu çerçevede geliştirilmiştir. Araştırmamızda veri toplama yöntemi olarak anket tekniği kullanılmıştır. Araştırmamızın evrenini, Türkiye genelinde Muhasebe Meslek mensuplarından hizmet alan mükellefler oluşturmaktadır. Ülke genelinde faaliyet gösteren tüm mükelleflere ulaşmak olanaklı olmadığından örneklem kapsamında Kasım 2018- Nisan 2019 tarihleri arasında toplam 197 adet anket mükelleflere mail yoluyla ulaştırılmıştır. Verilerin analizinde ise Smart PLS istatistik programı kullanılmıştır. Bu çalışmanın mali müşavirlere rehberlik etmesi beklenmektedir.

\section{LITERATÜR INCELEMESi}

Literatürde hizmetin birden fazla tanımına yer verilmiştir. Hizmet, 'bir tarafın diğerine arz ettiği somut olmayan faaliyet yada harekettir ( Kotler, 1997; Ok, 2011: 26). Hizmet, Zeithaml ve Bitner ve (2003)'e göre; süreçler, eylemler ve performanslar şeklinde tanımlanabilir. Mucuk (2001)'un hizmet tanımı ise; üretildiği yerde tüketilen, soyut, depolanma ve taşınma niteliği taşımayan mal yada fayda şeklindedir. Literatürde, hizmet kalitesine ilişkin de farklı farklı tanımlamalara rastlamak mümkündür. Kavram kısaca Parasuraman vd. (1985)'nin belirttiği gibi beklenti ve algılar arasındaki fark biçiminde ifade edilebilir (Eroğluer, 2013: 31). Bu manada beklenen ile algılanan kalite arasındaki negatif farkın, olumsuz; pozitif farkın ise olumlu kalite algısını oluşturduğu söylenebilir (Kılıç vd., 2013: 822). Sivakumar vd., (2014)'ne göre hizmet kalitesi, müşterinin ürünü kullanım öncesi beklentisi ve sonrasındaki deneyimi karşılaştırması ile ilgili bir kavramdır. Parasuraman vd., (1988); McDougall ve Levesque (1999); Grönroos (1984); vb. tarafından yapılan çalışmalarda görüldüğü üzere, hizmet kalitesinin birden fazla boyutlu oluşu hususu genel kabul görmektedir (Eroğluer, 2013: 34). Hizmet kalitesinin boyutlarına ilişkin literatürde en çok kabul gören ve ölçeği temel alınan çalışma Parasuraman vd., (1985) tarafından yapılan çalışma olmuştur (Eroğluer, 2013: 33).

Literatürde hizmet kalitesini ölçen birçok modelin geliştirildiği görülmektedir. Bu çalışma dahilinde bu modeller arasından en fazla kullanılan Grönroos Modeli, SERVPERF Modeli (Performansa Dayalı Model), Wyckoff, Sasser \& Olsen' nin Kalite Modeli, Normann' ın Kalite Modeli, Lehtinen \& Lehtinen Kalite Modeli yanısıra SERVQUAL Hizmet Kalitesi Ölçümü Modeli esas alınmıştır. Parasuraman vd., (1985) tarafından geliştirilen ve hizmet kalitesi boyutlarını içeren model, işletmelerin hizmet kalitelerinin müşteri ihtiyaçlarına yönelik analizi metoduyla ölçümüne yöneliktir. Parasuraman vd., (1988)'ne göre modelin temelini, algılanan hizmet kalitesi ile müşteri beklentileri arasındaki fark oluşturmaktadır. Modelin, müşterinin hizmet kalitesi algısını ölçtüğüne inanılmaktadır. Ayrıca müşterinin beklenti ve algıları arasındaki ilişkiyi gösterdiği belirtilmiştir (Kozub, 2008: 38). Parasuraman vd., (1985) tarafından yapılan çalışmada, kaliteli bir hizmet sunumu için müşteri hizmet beklentilerinin karşılanması veya beklentilerinden çok daha fazla hizmet sunulması gerektiği sonucuna ulaşılmıştır (Kılıç ve Eleren, 2010: 126). Hizmet kalitesinin ölçülmesi kapsamında ilk olarak on ölçüt belirlemişlerdir. Bu ölçütler; fiziksel varlıklar, güvenilirlik, yeterlilik (yetkinlik-yetenek), duyarlılık (heveslilik), erişilirlik/ulaşılabilirlik, nezaket, itibar, güvence (emniyet-güvenlik), iletişim ve müşteriyi anlamaktır (Resnick ve Griffiths, 2011: 150-151; Öztürk, 2005: 172; Eroğluer, 2013: 31).

Literatürde birbirleriyle bağlantıları olması sebebiyle bu on faktör, beş formatta toplanarak somut özellikler, heveslilik, güvenilirlik, empati ve güven şeklinde yeniden düzenlenmiştir (Kozub, 2008: 38). Parasuraman vd., (1991)'a göre ölçekteki beş boyut temel nitelikte olup bu boyutların birçok sektöre uygulanabilirliği bulunmaktadır. Bu kapsamda ölçek, literatürdeki hizmet kalitesinin ölçümüne ilişkin çalışmalarında sık sık kullanılmaktadır (Nart, 2006: 191). Bu ölçeğin tercih sebebi olmasına önemli bir etken de; müşterilerin beklentileri ve hizmet alımı sonrası hizmete ilişkin algısı arasında karşılaştırma yapabilme kolaylığı sağlamasıdır (Kozub, 2008: 39).

\section{VERI VE YÖNTEM, BULGULAR, ANALIZ}

Bu araştırmada, mali müşavirlik hizmetinden yararlanan kişilerin, aldıkları hizmete ilişkin tespitlerde bulunularak, bu hizmetten beklentilerinin ne olduğu ortaya koyulmaya çalışılmıştır. Çalışmada yer alan mükellef memnuniyetinin ölçümlemesi, literatürdeki memnuniyet ölçümleme tanım ve yöntemlerinden yararlanılarak incelenmiştir. Araştırmamızın evrenini, Türkiye genelinde Muhasebe Meslek mensuplarından hizmet alan mükellefler oluşturmaktadır. Ülke genelinde faaliyet gösteren tüm mükelleflere ulaşmak olanaklı olmadığından örneklem kapsamında Kasım 2018- Nisan 2019 tarihleri arasında toplam 197 adet anket mükelleflere mail yoluyla ulaştırılmıştır. 
Kavramsal modelde Mali müşavirlerin, hizmeti sunarken ortaya çıkabilecek hatalarının, mükellefin memnuniyetini etkileyeceğini, bu kavramlar arasında ilişki olduğu öne sürülmektedir. Hipotezler de bu çerçevede geliştirilmiştir.

Çalışmada Smart PLS programı kullanılmış olup analizler bu program vasıtasıyla anlamlandırılmıştır. Araştırma modeli verisinin uyumluluğunu test etmek için doğrulayıcı faktör analizleri de yapılmıştır. Analiz sonuçları, bir araya getirilen tüm faktör yükleri, $0.5^{\prime}$ ten daha büyük; ve bu faktör yüklerinin her bir p değeri 0.001'den daha küçük olduğunu göstermektedir. Bulunan bu sonuçlara göre, araştırma modelinin yakınsak geçerliliği kabul edilebilir (Hair vd., 2009). Fredriksson(2010) ve Jewell (2011) e göre, ayırt edici geçerlilikten bahsetmek için, her bir unsurun kendi gizli değişken yükü, onun diğer değişkenlerinin yükünden daha büyük olmalıdır. Çalışmada yer alan tüm yükler, kriterlerin ayırt edici geçerliliği kanıtlamadaki kullanışııığını kanıtlamaktadır. Aşağıdaki tabloda çapraz ve kombine yüklemeler gösterilmiştir:

Tablo 1: Çapraz ve Kombine Yüklemeler

\begin{tabular}{|c|c|c|c|c|c|c|c|c|}
\hline & hatamaj & hatamin & empati & güven & güvenilirlik & heveslilik & somut ö. & P value \\
\hline ALGILANAN1 & $-0,403$ & $-0,424$ & 0,468 & 0,390 & 0,533 & 0,535 & 0,808 & $<0.001$ \\
\hline ALGILANAN2 & $-0,320$ & $-0,447$ & 0,407 & 0,430 & 0,559 & 0,527 & 0,781 & $<0.001$ \\
\hline ALGILANAN3 & $-0,496$ & $-0,470$ & 0,463 & 0,580 & 0,612 & 0,627 & 0,785 & $<0.001$ \\
\hline ALGILANAN4 & $-0,246$ & $-0,385$ & 0,496 & 0,495 & 0,566 & 0,548 & 0,740 & $<0.001$ \\
\hline ALGILANAN6 & $-0,509$ & $-0,556$ & 0,590 & 0,618 & 0,791 & 0,664 & 0,605 & $<0.001$ \\
\hline ALGILANAN7 & $-0,445$ & $-0,523$ & 0,544 & 0,593 & 0,792 & 0,586 & 0,554 & $<0.001$ \\
\hline ALGILANAN8 & $-0,517$ & $-0,574$ & 0,541 & 0,642 & 0,814 & 0,656 & 0,597 & $<0.001$ \\
\hline ALGILANAN9 & $-0,421$ & $-0,486$ & 0,518 & 0,595 & 0,722 & 0,511 & 0,517 & $<0.001$ \\
\hline ALGILANAN10 & $-0,547$ & $-0,572$ & 0,645 & 0,555 & 0,629 & 0,790 & 0,524 & $<0.001$ \\
\hline ALGILANAN11 & $-0,514$ & $-0,633$ & 0,577 & 0,613 & 0,659 & 0,802 & 0,588 & $<0.001$ \\
\hline ALGILANAN12 & $-0,550$ & $-0,605$ & 0,539 & 0,564 & 0,624 & 0,790 & 0,603 & $<0.001$ \\
\hline ALGILANAN13 & $-0,534$ & $-0,553$ & 0,549 & 0,480 & 0,534 & 0,764 & 0,554 & $<0.001$ \\
\hline ALGILANAN15 & $-0,438$ & $-0,483$ & 0,522 & 0,798 & 0,670 & 0,533 & 0,531 & $<0.001$ \\
\hline ALGILANAN16 & $-0,515$ & $-0,573$ & 0,535 & 0,863 & 0,654 & 0,616 & 0,466 & $<0.001$ \\
\hline ALGILANAN17 & $-0,518$ & $-0,544$ & 0,604 & 0,854 & 0,656 & 0,617 & 0,548 & $<0.001$ \\
\hline ALGILANAN18 & $-0,520$ & $-0,528$ & 0,801 & 0,566 & 0,607 & 0,603 & 0,450 & $<0.001$ \\
\hline ALGILANAN19 & $-0,556$ & $-0,535$ & 0,798 & 0,583 & 0,596 & 0,606 & 0,504 & $<0.001$ \\
\hline ALGILANAN20 & $-0,390$ & $-0,402$ & 0,731 & 0,488 & 0,555 & 0,524 & 0,493 & $<0.001$ \\
\hline ALGILANAN21 & $-0,499$ & $-0,476$ & 0,839 & 0,533 & 0,517 & 0,577 & 0,481 & $<0.001$ \\
\hline ALGILANAN22 & $-0,457$ & $-0,487$ & 0,781 & 0,426 & 0,500 & 0,586 & 0,393 & $<0.001$ \\
\hline MAJÖR HATA 2 & 0,832 & 0,685 & $-0,494$ & $-0,492$ & $-0,536$ & $-0,587$ & $-0,403$ & $<0.001$ \\
\hline MINÖR HATA 3 & 0,609 & 0,747 & $-0,450$ & $-0,516$ & $-0,534$ & $-0,564$ & $-0,451$ & $<0.001$ \\
\hline MINÖR HATA 5 & 0,630 & 0,761 & $-0,476$ & $-0,557$ & $-0,522$ & $-0,556$ & $-0,366$ & $<0.001$ \\
\hline MINÖR HATA 7 & 0,590 & 0,735 & $-0,540$ & $-0,400$ & $-0,471$ & $-0,601$ & $-0,466$ & $<0.001$ \\
\hline MAJÖR HATA 8 & 0,804 & 0,620 & $-0,527$ & $-0,443$ & $-0,462$ & $-0,531$ & $-0,369$ & $<0.001$ \\
\hline MINÖR HATA 9 & 0,584 & 0,793 & $-0,437$ & $-0,413$ & $-0,507$ & $-0,528$ & $-0,385$ & $<0.001$ \\
\hline MINÖR HATA 11 & 0,642 & 0,794 & $-0,449$ & $-0,515$ & $-0,557$ & $-0,576$ & $-0,421$ & $<0.001$ \\
\hline MAJÖR HATA 12 & 0,793 & 0,628 & $-0,483$ & $-0,489$ & $-0,477$ & $-0,537$ & $-0,409$ & $<0.001$ \\
\hline MINÖR HATA 13 & 0,659 & 0,839 & $-0,516$ & $-0,544$ & $-0,609$ & $-0,661$ & $-0,489$ & $<0.001$ \\
\hline MINÖR HATA 15 & 0,629 & 0,788 & $-0,504$ & $-0,525$ & $-0,539$ & $-0,605$ & $-0,457$ & $<0.001$ \\
\hline
\end{tabular}

Ölçeğin güvenilirliğini ölçmek için, Composite Reliability (CR) katsayısı ve Cronbach Alpha katsayısı hesaplanır (Bagozzi ve Yi, 1988). Bagozzi ve Yi (1988) CR katsayısının 0.6 dan büyük olması gerektiğini belirtmiş ve buna ilaveten Nunally (1978) CR katsayısı için limiti 0.7’ye çıkarmış ve yapılacak çalışmalardaki değerin 0.7 den büyük olması gerekliliğini önermiştir. İkinci güvenilirlik göstergesi olarak da Cronbach Alpha katsayısı hesaplanmaktadır. Anderson(1988) ise sonuçlara göre Cronbach Alpha katsayısının 0.6 dan daha büyük olması gerektiğini önermiştir. 
Tablo 2: Bileşik Güvenilirlik, Cronbach Alpha ve AVE

\begin{tabular}{|l|c|c|c|}
\hline & Cronbach's Alpha & Composite Reliability & Average Variance Extracted (AVE) \\
\hline hatamaj & 0,738 & 0,851 & 0,656 \\
\hline hatamin & 0,892 & 0,916 & 0,609 \\
\hline empati & 0,850 & 0,893 & 0,626 \\
\hline güven & 0,790 & 0,877 & 0,704 \\
\hline güvenilirlik & 0,840 & 0,887 & 0,611 \\
\hline heveslilik & 0,795 & 0,866 & 0,619 \\
\hline somut & 0,786 & 0,860 & 0,606 \\
\hline
\end{tabular}

Yapısal eşitlik (SEM) analizi, çalışmamızda yer alan unsurların: Majör ve Minör hizmet hatalarının, algılanan hizmet kalitesi boyutlarından somut (fiziksel) özellikler, güvenilirlik, heveslilik, güven, ve empati arasındaki ilişkileri araştırmaktadır. SEM analizi sonuçlarına göre etkenler arasındaki ilişkinin değerlendirmesi aşağıdaki şekilde gerçekleşmiştir:

Analiz sonuçlarına göre; majör hizmet hatası ile algılanan hizmet kalitesi boyutlarından sırasıyla fiziksel (somut) özellikler arasında ( $\beta=-0,100$ $p>0,05)$, güvenilirlik arasında $(\beta=-0,168 p<0,05)$, heveslilik arasında $(\beta=-0,226 p<0,01)$, güven arasında $(\beta=-0,214 p<0,1)$, empati arasında $(\beta=-$ $0,343 p<0,01)$ negatif yönlü anlamlı bir ilişki vardır.

Minör hizmet hatası ile algılanan hizmet kalitesi boyutlarından sırasıyla fiziksel (somut) özellikler arasında $(\beta=-0,447$ ( $p<0.01)$, güvenilirlik arasında $(\beta=-0,553(p<0.01)$, heveslilik arasında $(\beta=-0,572(p<0.01)$, güven arasında $(\beta=-0,468(p<0.01)$, empati arasında $(\beta=-0,346(p<0.01)$ ise negatif yönlü anlamlı bir ilişki vardır.

Buna göre meslek Mensuplarını hizmeti sunarken yaptıkları hizmet hataları arttıkça mükellefler tarafından algılanan hizmet kalitesi azalmaktadır. Görüldüğü gibi değişkenlerin tümü arasında istatistiksel olarak anlamlı ve beklenen durumu gösteren sonuçlar tespit edilmiştir.

Tablo 3: Yol Katsayıları ve P Değerleri

\begin{tabular}{|c|c|c|c|c|c|}
\hline & Yol & Yol Katsayısı & $P$ değeri & $\mathrm{Q}^{2}$ (=1-SSE/SSO) & Geçerlilik \\
\hline Hipotez 1 & hatamin〉>>fiziksel ö. & $\beta=-0,477$ & 0 & 0,171 & Desteklenmiştir \\
\hline Hipotez 2 & hatamin >>>güvenilirlik & $\beta=-0,553$ & 0 & 0,293 & Desteklenmiştir \\
\hline Hipotez 3 & 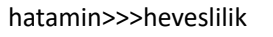 & $\beta=-0,572$ & 0 & 0,341 & Desteklenmiştir \\
\hline Hipotez 4 & hatamin >>>güven & $\beta=-0,468$ & 0 & 0,278 & Desteklenmiştir \\
\hline Hipotez 5 & hatamin >>>empati & $\beta=-0,346$ & 0 & 0,241 & Desteklenmiştir \\
\hline Hipotez 6 & hatamaj〉>>fiziksel ö. & $\beta=-0,100$ & 0,323 & 0,171 & Desteklenmemiştir \\
\hline Hipotez 7 & hatamaj>>>güvenilirlik & $\beta=-0,168$ & 0,043 & 0,293 & Desteklenmiştir \\
\hline Hipotez 8 & hatamaj»>>heveslilik & $\beta=-0,226$ & 0,001 & 0,341 & Desteklenmiştir \\
\hline Hipotez 9 & hatamaj>>>güven & $\beta=-0,214$ & 0,083 & 0,278 & Desteklenmemiştir \\
\hline Hipotez 10 & hatamaj>>>empati & $\beta=-0,343$ & 0 & 0,241 & Desteklenmiştir \\
\hline
\end{tabular}

Yapısal modelin uygunluğu kapsamında Q2 kriteri modelin tahmin etme gücünü gösterir. Yapısal uygunluğu kabul edilebilir modeller, modelin endojen yapıları ile ilgili endeksleri tahmin etme kabiliyetine sahip olmaları gerekmektedir. Q2 değeri, modelin bütün endojen yapıları için hesaplanmalıdır. Modelin tüm endojen değişkenleri için Q2 değerleri Tablo 4.3.4.2 'de gösterilmektedir. tahmin etme gücünü belirten Q2 için $0.02,0.15$ ve 0.30 değerleri sırayla zayıf, orta ve güçlü değerler olarak tanımlanmıştır. Q2 için elde edilmiş değerlere göre, modelin endojen değişkenleri için tahmin etme gücü kabul edilebilir ve yapısal modelin iyi uygunluğu onaylanabilir.

Tabloyu incelediğimizde, mali müşavirlerin hizmeti sunarken yapmış oldukları hizmet hataları, mükelleflerin algıladığı hizmet kalitesini negatif yönde anlamlı yönde etkilenmektedir. Bu sonuçlar, $\mathrm{H1}$, H2, H3, H4, H5, H7, H8 ve H10 hipotezlerinin desteklendiğini göstermektedir.

\section{SONUÇ}

Çalışmamızda da bu temelden hareketle, -araştırmada majör ve minör olarak ayrılan- hizmet hatalarının, mükellefin algıladığı hizmet kalitesini (memnuniyetini) ne şekilde etkilediği araştııımıştı. Bu amaçla Türkiye genelinde 197 mali müşavirlik hizmet alan kişiye uygulanan anket ile elde edilen veriye, uygulanan analizler sonucunda ulaşılan bulgularla; Mali müşavirlik hizmeti verilmesi esnasında yapılan hizmet hatalarının mükellefin algılanan hizmet kalitesini düşürerek memnuniyetini negatif yönde etkilediği sonucuna ulaşılmışır. 
Bu bulgular, muhasebe meslek mensuplarının (mali müşavirlerin) kendi kurumlarında ve iş yerlerinde sunmuş oldukları hizmete ilişkin majör veya minör nitelikli hizmet hatalarını azaltacak bazı çalışma ve faaliyetlerin yürütülmesinin, mükellef memnuniyetinin artırılması için büyük öneme sahip olduğunu ortaya koymaktadır.

\section{KAYNAKLAR}

Anderson R., Tatham R., Hair J., Babin B., Black B., (1998), Multivariate Data Analysis London, Prentice Hall.

Bagozzi R.P., Yi Y., (1988), On The Evaluation of Structural Equation Models, Journal of the Academy of Marketing Science, 16(1), 74-79.

Banar Kerim, Ekergil Vedat, Muhasebe Meslek Mensuplarının Hizmet Kalitesi: Sunulan Hizmetlerin Kalitesi İle Müşteri Memnuniyeti İlişkisi Eskişehir Uygulaması, Anadolu Üniversitesi Sosyal Bilimler Dergisi Cilt/Vol.:10-Sayı/No:1:39-60(2010), S.40

Eroğluer Kemal; (2013). Hizmet Kalitesi Algısının Kurumsal İmaja Etkisi Üzerine Hizmet Sektöründe Bir Araştırma. Anadolu Üniversitesi Sosyal Bilimler Dergisi, Cilt 13, Sayı 4, Ss. 29-46.

Fredriksson A., (2010) Soft And Hard Information in Bank-Firm Relationships, The Effects of Relationship Intensity and Reporting Conservatism on Loan Pricing And Relationship Value, Turku School of Economics.

Gronroos C.; (1984). A Service Quality Model and its Marketing İmplications. European Journal of Marketing, 18(4), Pp. 36-44.

Hair J., Black W.C., Babin B.J., Anderson R.E.,(2009). Multivariate Data Analysis.

Jewell D. V., (2011). Guide To Evidenced-Based Physical Therapist Practice(2. Edition). Jones And Bartlett Publishers, Ontario, 721.

Kılıç Burhan Ve Eleren Ali; (2010). Termal Otel İşletmelerinde Hizmet Kalitesinin Ölçülmesi. Süleyman Demirel Üniversitesi, İktisadi Ve İdari Bilimler Fakültesi Dergisi, C.15, S.3, Ss.119-142.

Kılıç Burhan, Ok Serap, Sop Serhat Adem; (2013). Otel İşletmelerinde Müşteri Şikayetlerinin Değerlendirilmesi ve Hizmet Kalitesi Algısının Müşteri Sadakati Üzerine Etkisi. Gaziantep University Journal Of Social Sciences, 12(4), Ss. 817-836.

Kotler P.; (1997)., Marketing Management: Analysis, Planning, Implementation, and Control, Upper Saddle River, Nj: Prentice Hall.

Kozub Kristen A. Riscinto; (2008). The Effects of Service Recovery Satısfactıon on Customer Loyalty and Future Behavıoral Intentıons: An Exploratory Study in The Luxury Hotel Industry. Auburn University, Auburn, Dissertation of Doctor of Philosophy, Alabama.

Mcdougall H. G. G. And Levesque J. T.; (1999). Waiting For Service: Effectiveness Of Recovery Strategies. International Journal of Contemporary Hospitality Management, Volume 11, No 1, Pp. 6-15.

Mucuk I..; (2001). Pazarlama IIlkeleri, Türkmen Kitabevi Yayınları, İstanbul.

Nart Sima; (2006). Algılanan Hizmet Kalitesinin Müşteri Değerlendirme Sürecine Yansımaları ve Sadakat Üzerindeki Etkisi: Havayolu Endüstrisinden Bulgular. Uludağ Üniversitesi, İktisadi ve İdari Bilimler Fakültesi Dergisi, Cilt Xxv, Sayı 2, Ss. 185-216.

Nunnally J. C., (1978). Psychometric Theory. New York. Ny: Mcgraw-Hill

Öztürk Yüksel, Seyhan Kadir; (2005). Konaklama İşletmelerinde Sunulan Hizmet Kalitesinin Servqual Yöntemi İle Ölçülmesi. Anatolia: Turizm Araştırmaları Dergisi, Cilt 16, Sayı 2, Güz: Ss. 170-182.

Parasuraman A., ZeithamI V.A. And Berry L. L.; (1985). A Conceptual Model of Service Quality and its Implications for Future Research Journal of Marketing, Volume 49, Pp. 41-50

Parasuraman A., Zeithaml V. And Berry L.; (1988). Servqual: A Multiple İtem Scale for Measuring Consumer Perceptions of Service Quality. Journal of Retailing, 64(1), Pp. 12-40

Parasuraman A, Zeithamlvalerie A., Berry Leonard L.; (1991). Refinement and Reassessment of the Servqual Scale. Journal of Retailing, Vol.67, No:4, Pp.420-450.

Resnick S. M. and Griffiths M. D.; (2011). Service Quality in Alcohol Treatment. A Research Note. International Journal of Health Care Quality Assurance, 24(2), Pp. 149-163.

Sivakumar K., Li, M. And Dong B.; (2014). Service Quality: The Impact of Frequency, Timing, Proximity, And Sequence of Failures and Deligths", Journal of Marketing, Vol. 78, (January), Pp. 41-58. 168

Zeithaml V. A. and Bitner M. J.; (2003), Services Marketing, (Third Edition) McGraw-Hill, pp. 185-215. 